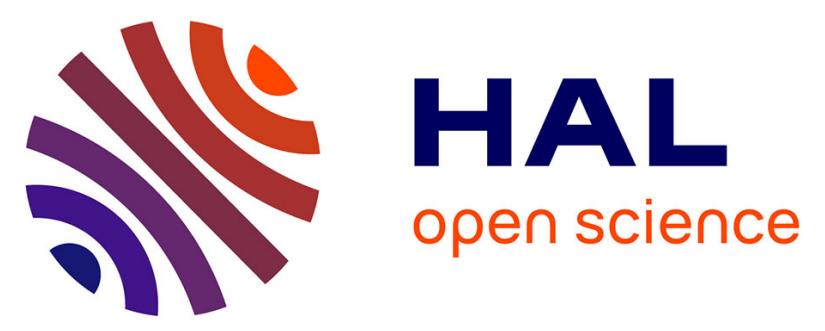

\title{
A GIS-based integrated approach predicts accurately post-fire Aleppo pine regeneration at regional scale
}

Kostas Poirazidis, Zografou, Kordopatis, Dionissios Kalivas, Arianoutsou, Kazanis, Korakaki

\section{- To cite this version:}

Kostas Poirazidis, Zografou, Kordopatis, Dionissios Kalivas, Arianoutsou, et al.. A GIS-based integrated approach predicts accurately post-fire Aleppo pine regeneration at regional scale. Annals of Forest Science, 2012, 69 (4), pp.519-529. 10.1007/s13595-012-0222-3 . hal-00930871

\section{HAL Id: hal-00930871 https://hal.science/hal-00930871}

Submitted on 1 Jan 2012

HAL is a multi-disciplinary open access archive for the deposit and dissemination of scientific research documents, whether they are published or not. The documents may come from teaching and research institutions in France or abroad, or from public or private research centers.
L'archive ouverte pluridisciplinaire HAL, est destinée au dépôt et à la diffusion de documents scientifiques de niveau recherche, publiés ou non, émanant des établissements d'enseignement et de recherche français ou étrangers, des laboratoires publics ou privés. 


\title{
A GIS-based integrated approach predicts accurately post-fire Aleppo pine regeneration at regional scale
}

\author{
Kostas S. Poirazidis • Konstantina Zografou • \\ Panagiotis Kordopatis • Dionissios P. Kalivas • \\ Margarita Arianoutsou • Dimitrios Kazanis • \\ Evangelia Korakaki
}

Received: 25 October 2011 / Accepted: 17 May 2012 /Published online: 14 June 2012

(C) INRA / Springer-Verlag France 2012

\begin{abstract}
- Context This study investigates post-fire natural regeneration of Aleppo pine (Pinus halepensis) forests at Ilia region (Peloponnesus, Greece) following the catastrophic fire of 2007. - Aims The objective of this study is the prediction of $P$. halepensis post-fire regeneration at a regional scale through
\end{abstract}

\footnotetext{
Handling Editor: Eric Rigolot

Contribution of the co-authors K. Poirazidis: Supervising the project $(100 \%)$, designing of the project $(50 \%)$, preliminary works $(35 \%)$, writing the paper (35\%), and running part of the data analysis (50\%). K. Zografou: Designing part of the project (10\%), field work (50\%), preliminary works $(30 \%)$, writing the paper $(25 \%)$ and running part of the data analysis $(20 \%)$.

P. Kordopatis: Designing part of the project (10\%), field work (50\%), preliminary works $(35 \%)$, writing the paper $(10 \%)$, running part of the data analysis (5\%).

D. Kalivas: Designing part of the project (20\%), writing the paper $(25 \%)$, and running part of the data analysis $(25 \%)$.

M. Arianoutsou: Designing part of the project (5\%), writing the paper (5\%).

D. Kazanis: Designing part of the project (5\%).

E. Korakaki: Coordinating the research project $(100 \%)$.
}

K. S. Poirazidis $(\bowtie) \cdot K$. Zografou $\cdot$ P. Kordopatis $\cdot$ E. Korakaki WWF Greece,

21, Lembessi St.,

11743 Athens, Greece

e-mail: k.poirazidis@wwf.gr

K. Zografou

e-mail: ntinazografou@yahoo.co.uk

P. Kordopatis

e-mail: p.kordopatis@wwf.gr

E. Korakaki

e-mail: e.korakaki@wwf.gr

\section{K. S. Poirazidis}

Department of Environmental Technology and Ecology,

Technological Educational Institute of Ionian Islands,

2 Calvou Sq,

29100 Zakynthos, Greece an integrated geographic information systems (GIS) model as a basis for post-fire management plans.

- Methods The model was developed in three interconnected stages: (1) field data collection, (2) development of two prediction models (based on interpolation of field data and multicriteria evaluation (MCE) that combined factors known to
D. P. Kalivas

Department of Natural Resources Management and Agricultural

Engineering, Agricultural University of Athens,

75, Iera Odos,

11855 Athens, Greece

e-mail: kalivas@aua.gr

M. Arianoutsou • D. Kazanis

Department of Ecology and Systematics,

National and Kapodistrian University of Athens,

Panepistimiopolis, Ilisia,

15784 Athens, Greece

\author{
M. Arianoutsou \\ e-mail: marianou@biol.uoa.gr \\ D. Kazanis \\ e-mail: dkazanis@biol.uoa.gr
}


affect regeneration), and (3) combination of applied models using Bayesian statistics.

- Results Post-fire pine regeneration presented high variation among the studied plots. Redundancy analysis revealed the positive effect of fallen branches and a negative correlation with altitude. Both modeling approaches (geostatistical and MCE) predicted the post-fire pine regeneration with high accuracy. A very significant correlation $(r=0.834$, $p<0.01$ ) was found between the combined final model and the actual number of counted seedlings, illustrating that less than $10 \%$ of the studied area corresponds to sites of very low post-fire pine regeneration.

- Conclusions The combination of GIS models increased the prediction success of different levels of pine regeneration. Lowaltitude areas with low grass cover overlying tertiary deposits were proved the most suitable for pine regeneration, while stands developing on limestone proved least suitable. The proposed methodology provides management authorities with a sound tool to quickly assess Aleppo pine post-fire regeneration potential.

Keywords Redundancy analysis - Geostatistics - MCDA . AHP $\cdot$ Regeneration $\cdot$ Pinus halepensis

\section{Introduction}

Mediterranean ecosystems, due to a combination of natural factors and anthropogenic interventions, are characterized by high spatial heterogeneity. Wildfire is one of the main drivers for the current landscape mosaic. Detailed studies regarding post-fire regeneration (Pausas et al. 2004a) indicate that most Mediterranean ecosystems show high resilience to wildfires. However, the remarkably increasing rate of wildfire frequency and severity during recent decades in the region could cause serious ecosystem degradation, especially in cases where erosion hazard is high and poor post-fire regeneration is observed (Ruiz-Gallardo et al. 2004). Hence, forest fires may be considered nowadays as one of the major disturbance factors in the Mediterranean region, raising a concern about their ecological and socio-economic impacts (Moreira et al. 2011).

Post-fire regeneration processes differ among regions since different environmental factors play a critical role affecting regeneration patterns (Casady et al. 2010). Therefore, detailed examination of the characteristics of the Mediterranean but also more focused analyses following specific wildfires can improve our understanding of the post-fire regenerations processes. Topographical, geological, and remote sensing data on pre-fire vegetation (species composition, cover, etc.) provide important site-specific information for post-fire vegetation evaluations. Other factors have also been found to affect the post-fire regeneration such as fallen wood and branches (Pausas et al. 2004a), obligate resprouter species cover (e.g., evergreen sclerophyllous shrubs and perennial grasses; Kazanis 2005), legume species richness and abundance (Arianoutsou and Thanos 1996). Many researchers have used different statistical methods to study the influence of different factors in post-fire regeneration including $t$ test, analysis of variance (Tsitsoni 1997), regression trees (Casady et al. 2010), detrended correspondence and canonical correspondence analysis (Baeza et al. 2007), geographically weighted regression (Kupfer and Farris 2007), stepwise regression (Pausas et al. 2004a), Kendall bivariate correlation analysis, and distance correlation analysis (Xie et al. 2008). The results indicate that many environmental factors (like fire variability, patchiness of different successional states, geological substrate, ground slope, and woody vegetation cover) affect positively or negatively post-fire regeneration and finally define the post-fire patches of the new forested landscape. Large wildfires usually create a complex and highly heterogeneous post-fire landscape regarding the differences on the natural regeneration success. Reliable prediction models for post-fire vegetation recovery at regional scale, based on geographic information systems (GIS), are necessary in order to predict the aforementioned effects (Arianoutsou et al. 2011) and assign spatial reference to them. The data derived from these models comprise a great assistance to decision makers, as they can identify where restoration should take place and whether it should be based solely on natural regeneration or supplementary reforestation (planting and sowing; Corona et al. 2008).

GIS and remote sensing (RS) offer the most suitable environment to handle problems at a regional scale. GIS and RS have been used extensively in post-fire applications to estimate the burned areas (e.g., Mitri and Gitas 2006); to identify areas of high erosion after fire (Ruiz-Gallardo et al. 2004), or to evaluate the post-fire ecosystem recovery (Dìz-Delgado et al. 2003). Many studies have developed a variety of applications and indices to monitor the post-fire environment after fire occurrence (fire severity) or fire effects (burn severity) using low- and medium-resolution satellite data (Landsat TM/ETM+or SPOT) or, more recently, high-spatial-resolution satellite imagery (e.g., Ikonos, QuickBird; Lentile et al. 2006). Additionally, mathematical models and multi-criteria methods can describe adequately the complex combined influence of biotic and abiotic factors, a crucial factor in post-fire forest regeneration. Nevertheless, very few studies have been based on such an integrated approach. Multi-criteria decision models (MCDM) and especially analytic hierarchy process (AHP) and ordered weighted averaging (OWA) are receiving increasing attention in dealing with complex problem issues, such as environmental planning (Malczewski 1996) and land-use suitability assessment (Malczewski 2006), prioritizing areas for forest landscape restoration (Orsi and Geneletti 2010), forest management (Kangas and Kangas 2005), and forest conservation (Kalivas et al. 2010). MCDM based on GIS has been also used to evaluate post-fire Aleppo pine forest resilience at regional scale (Arianoutsou et al. 2011). Additionally, Kriging theory (Webster and Oliver 2007) has been repeatedly applied in evaluating forest ecosystem 
Fig. 1 Study area, Ilia prefecture (SW Greece) burned in 2007 (in gray): 84 plots (white circles) inside the burned Aleppo pine (P. halepensis) forests (in black) were sampled

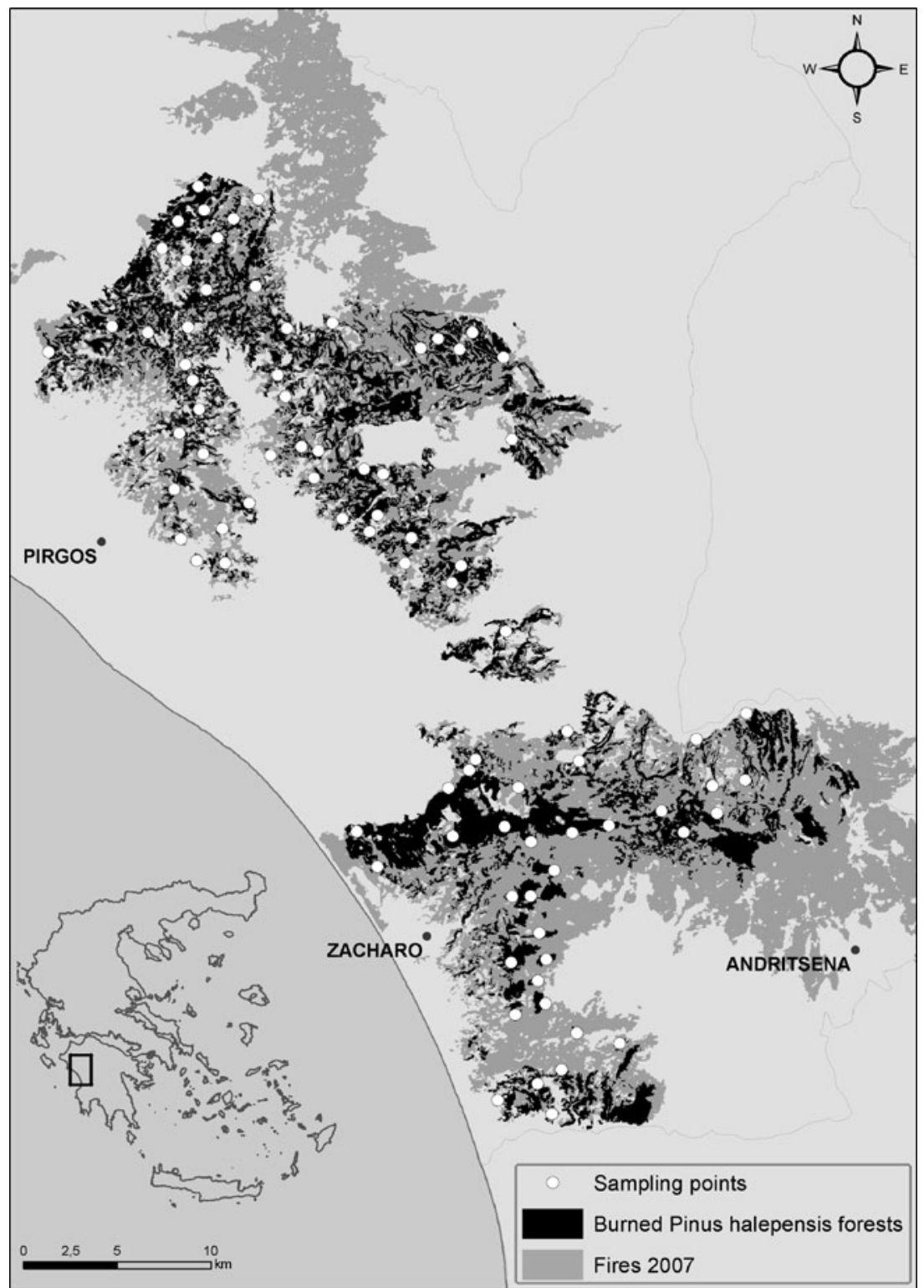

characteristics and more specifically in evaluating forest biomass (Sales et al. 2007) and forest damage (Kohl and Gertner 1997) and in estimating forest volume (Maselli and Chiesi 2006).

Greece, being part of the Mediterranean basin, has witnessed many fire episodes. Following the 2007 catastrophic fires, where 22,678 ha of Pinus halepensis forests were damaged in Ilia region (Peloponnesus, south Greece), the public demand for effective post-fire management plans became acute. Therefore, the development of an integrated GIS-based model was deemed necessary. Such model would identify the natural post-fire regeneration of $P$. halepensis, becoming a useful tool for the application of restoration measures. The model that was developed has the capacity to predict and represent spatially, at a prefecture level, the regeneration patterns, taking into account not only the most important factors which influence post-fire forest regeneration and their interaction (multi-criteria part), but also the spatial autocorrelation of the forest regeneration dynamics (geostatistical part).

\section{Materials and methods}

\subsection{Study area}

Our study area refers to the burned area of the prefecture of Ilia $\left(21^{\circ} 26^{\prime} 25.84^{\prime \prime} \mathrm{E}\right.$ and $\left.37^{\circ} 40^{\prime} 7.244^{\prime \prime} \mathrm{N}\right)$, located in southwest Greece (Fig. 1). It covers 22,678 ha, of which 1,479 ha have been included in the Natura 2000 network (GR2330002 OROPEDIO FOLOIS, GR2330004-OLYMPIA, and GR2330005-THINES KAI PARALIAKO DASOS ZACHAROS, LIMNI KAIAFA, STROFYLIA, 
KAKOVATOS). The entire study area is characterized by a typical heterogeneous cultural landscape, combining $P$. halepensis forest stands, of different size and age, with cultivations, primarily olive yards. The altitude varies between 0 and $775 \mathrm{~m}$ and the climate is typically Mediterranean, with mean annual temperature of $17.4^{\circ} \mathrm{C}$ and mean annual precipitation of $920 \mathrm{~mm}$.

\subsection{General framework}

The methodology applied in this study consisted of three interconnected stages. (A) Data collection, which included both desktop analysis of pre-fire forest structure data and field sampling of pine regeneration 2 years after the fire in order to provide (1) a control sample for the evaluation of the model and (2) support to the next stages of analysis (spatial interpolation of measurements and identification of important environmental factors affecting pine regeneration). (B) Statistical analysis and prediction modeling, which included two prediction models that were developed concurrently: (1) prediction of regeneration, based on spatial interpolation of measured data of pine regeneration and (2) a multi-criteria analysis, based on factors that redundancy analysis indicates affect natural regeneration. (C) Models' integration, which combined the two fore mentioned models using Bayesian statistics to identify areas with different levels of natural post-fire pine regeneration.

\subsubsection{Data collection}

Analysis of high-resolution satellite photos (1 year before the fire) and heads-up digitizing in GIS environment identified three main structural characteristics of the pre-fire forest structure, which determine post-fire regeneration: (a) the age of the forest when burned, where three classes were recognized $(1=$ very young, i.e., $1-4$ years old; $2=$ young, i.e., 5-20 years old; $3=$ old forest, i.e., more than 20 years old), (b) the canopy closure of the forest (low, moderate and high), and (c) the percentage of mature tree presence inside the digitized polygons (nine categories: $0,5,10,15,20,25,30,35$, and $40 \%$ ). In addition, the digital elevation model of the study area was created from the digitized contours (20-m interval) and slope and aspect maps were generated. Finally, the geology map of the study area, issued by the Greek Institute of Geology and Mineral Exploration at 1983, was also digitized.

The second phase of data collection included field sampling 2 years after the fire (2009). A stratified random sampling scheme was applied in the study area through GIS, using a simple rejection method algorithm, leading to the selection of 84 plots of burned pine forest. Taking into account the abrupt spatial pattern of the burned units, the sampling sites were finally distributed spatially almost equally (Fig. 1). To avoid bias due to local micro-heterogeneity, sampling at each site was carried out in five circles selected to form the shape of a cross.
Each circle had a $2.5 \mathrm{~m}$ radius and was placed $15 \mathrm{~m}$ away from the other, covering an area of $20 \mathrm{~m}^{2}$ (i.e., $100 \mathrm{~m}^{2}$ were finally sampled in each plot). In order to be able to evaluate the degree of environmental factors influence on natural pine regeneration, the following data was recorded in each one of the sampling plots: number of $P$. halepensis seedlings, coverage (percent) of fallen wood and branches, percentage cover of total vegetation, number of Asphodelus sp. (individuals), percentage cover of dominant woody species, percentage cover of grasses, percentage cover of legume species, percentage cover of herbs, and rock coverage (percent).

\subsubsection{Statistical analysis and prediction modeling}

The second stage involved the application of ordination techniques in order to analyze the data collected and explore the environmental factors affecting natural post-fire $P$. halepensis regeneration. Detrended correspondence analysis using CANOCO software revealed that taxa abundance presents a linear response to the environmental data set. Forward analysis of redundancy analysis (RDA), a constraint version of principal components analysis, reveals the most significant $(p<0.05)$ and free from collinearity (1,000 iterations of Monte Carlo test) environmental variables only for species sufficiently influenced by them (fit $=20 \%$ ). A subtotal of them was selected for the subsequent analyses. The position of $P$. halepensis in the resulting diagram (Fig. 2) indicates its ecological optima: the closest an environmental variable is, the greater its abundance or probability of occurrence.

Geostatistical model A combination of various predictive models based on GIS was used to predict Aleppo pine regeneration at landscape level. Initially, based on the field data collected from the 84 scattered plots, geostatistical models were developed. The main challenge was to interpolate the measured values of $P$. halepensis seedlings in the totally burned area. Additionally, a subtotal of the parameters identified as important

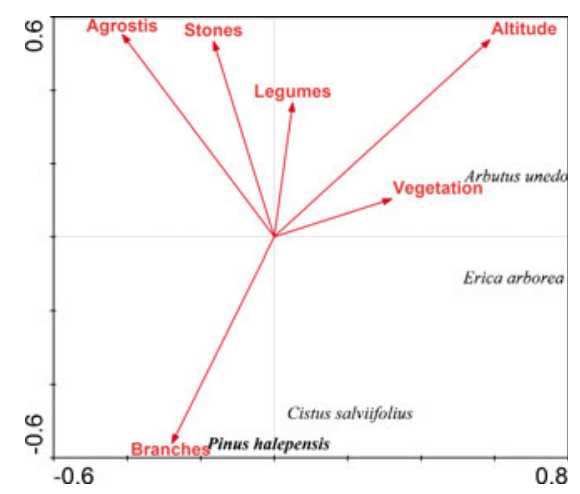

Fig. 2 Ordination biplot (RDA) of species and environmental variables (arrows). The position of $P$. halepensis indicates its ecological optima: the closest an environmental variable is, the greater its abundance or probability of occurrence 
for regeneration using RDA was interpolated geostatistically and the resulting thematic maps were used in the following multicriteria evaluation model.

The Kriging methodology was chosen due to its advantages, as every Kriging estimation value is accompanied by a corresponding Kriging standard deviation, compared to other spatial interpolation methods (such as inverse distance weighting). An experimental and its associated, best adapted, theoretical semi-variogram model were calculated for each variable. Using the theoretical semi-variogram parameters, values of a variable at non-sampled sites were estimated through the Kriging theory (Webster and Oliver 2007). The estimated value was calculated as a weighted linear combination of the neighboring sampled values. The calculation of the Kriging weight of each surrounding value, based on the spatial relationship of the data, was chosen so that the estimated value would be unbiased and the estimated prediction variance would be minimized. Ordinary Kriging was used for the interpolation of the data. It was chosen over Simple Kriging since it requires neither knowledge nor stationary of the mean over the entire study area. The accuracy of the spatial interpolation was audited by implementing a cross-validation technique, the jack-knifing. The following indices were calculated, based on differences between observed and estimated values: mean error (ME) and root mean square error (RMSE).

Multi-criteria evaluation (MCE) of the landscape A multicriteria evaluation method was applied to rank areas with respect to their potential pine regeneration after fire. The GIS-based multi-criteria analysis involved four interrelated steps (Malczewski 1996): (a) creation of evaluation criteria, (b) standardization of the evaluation criteria, (c) use of specific weights in each of the criteria according to their importance, and (d) combination of the standardized maps and their associated weights to an overall map. The identification of criteria was based on RDA analysis (see 3.2) as well as on experts' opinion and literature review. All factors (qualitative and quantitative) were spatially projected (e.g., spatial interpolation) to enable integration through GIS. Two sub-groups of factors were indentified: Group A contained four factors affecting the production and distribution of $P$. halepensis seeds: (1) pre-fire forest structure, (2) terrain slope, (3) geological substrate, and (4) altitude. The first factor, which was the most demanding to define, was the most influential. It was based on a combination of the prefire forest age, the canopy closure and the percentage of mature Aleppo trees and was transformed to an ordinary ascending scale from 1 to 23 , where " 1 " is the least and " 23 " is the most suitable area for post-fire regeneration. Group B consisted of four factors affecting the germination success and the survival of the seedlings, namely the cover of: (a) Quercus coccifera and Arbutus unedo, (b) grasses, (c) stones, and (d) fallen wood and branches.

Since evaluation criteria are usually non-commensurate, a standardization of raw data was required to make various criterion maps comparable (Malczewski 1996). Factors of groups A and B (both qualitative and quantitative) were transformed using fuzzy criteria into a single common scale (Jiang and Eastman 2000). The decision of the appropriate fuzzy function and membership was evaluated using scatter plots of the measured mean pine seedlings per square meter to each environmental factor (Poirazidis et al. 2011). The relative significance of factors is given by a set of weights. The set of weights $(W)$ should be such that: $0 \leq W_{\mathrm{i}} \leq 1$ and $W_{1}+W_{2}+\ldots W_{\mathrm{i}}=$ 1. There are many uncertainties involved into a multi-criteria analysis, such as the ranking of the importance of each factor. Therefore a number of methods have been developed for assigning weights to evaluation criteria (Hwang and Yoon 1981). In this study, the relative weights assigned to factors followed the AHP methodology (Saaty 1987). In AHP the selected factors were compared on a pairwise basis and the rating of the preference was expressed on a nine-grade scale. Thus, response matrices were produced; one for each group of factors, and a consistency ratio (CR), which expresses the degree of uncertainty, was computed. Pairwise comparisons are considered inconsistent when $\mathrm{CR}>0.1$. Using the calculated weights, the two resulted criterion maps (group A and group B) were combined into an integrated, weighted standardized evaluation map, using IDRISI software (Eastman 1995).

MCE model uncertainty analysis The uncertainty involved in the implemented multi-criteria analysis lies in four different sources: selection of the criteria, standardization of the criteria values, criteria weights determination (Saltelli et al. 2000), and determination of the relative importance of group $\mathrm{A}$ and group B. The control of the inherent uncertainty involved in the aforementioned sources, was dealt in this study as follows: (a) RDA analysis and expert opinion were incorporated for the selection of the criteria. (b) Fuzzy logic was integrated into the model as it presents an effective and structural way dealing with decisions involving environmental qualitative characteristics (Burrough and McDonnell 1998). Fuzzy membership function selection was based on scatter plots analysis of the collected data which, as opposed to Boolean approaches, offers the comparative advantage of optimum representation of parameters' uncertainty. (c) AHP weighting and the associated consistency ratios that were produced consisted of a structured means for the final decision, by weakening the contribution of criteria of minor importance and highlighting the significant ones. Thus, it was included in the analysis. (d) The uncertainty involved in the comparative significance of each group (A and B) to the decision problem was faced through sensitivity analysis including a repetitive evaluation of the model, each time under different proportional weights. Hence, in order to explore the outputs between different weights, a variation equal to $10 \%$ for each run was applied to the relative contribution of each group. A set of nine evaluation runs was conducted. Each time, a single MCE 
classification map was generated. These results were evaluated by the recorded regeneration.

\subsubsection{Models integration: geostatistical and MCE models}

At the final stage of the research, geostatistical and MCE models were combined on the basis of Bayesian statistics through GIS environment using the following mathematical formula (Osborne et al. 2001):

Final Model $=\frac{1}{1+e\left(\log \frac{1-\text { MCE model }}{\text { MCE model }}-\log \frac{\text { Geostatistical model }}{1-\text { Geostatistical model }}\right)}$

This technique allows the revision of a priori probability calculation (for example, from a model), based on a new (post) subsequent probability from the second model. The technique improved the results of the classification and the reduction of bias, when the sample was non-fully representative of the population to be characterized (Pereira and Itami 1991). The final model map was classified into ten equal interval categories according to seedlings density (where $1=$ lowest density and $10=$ highest density).

\section{Results}

\subsection{Post-fire state of regeneration}

Two years after the fire, vigorous pine regeneration was observed on many plots. A total of 19,634 P. halepensis seedlings were recorded during the field campaign on the 84 plots, with a mean value of $233.7 \pm 423.3$ (sd) and pine density (individuals per square meter) per site of $2.7 \pm 5.9$ (sd). However, the distribution was not equal among these sites (Fig. 3). At the majority of the sites (75\%), no more than 283 seedlings (pine density $=3.2$ individuals $/ \mathrm{m}^{2}$ ) were recorded, while at $50 \%$ of the plots pine density was lower (less than 0.9 individuals $/ \mathrm{m}^{2}$ ). A significant difference was found in the recorded regeneration among sites on tertiary deposits (post hoc Games-Howell test, $p<0.001$ ) but not among sites on limestone and flysch $(p=0.972)$. High numbers of $P$. halepensis seedlings $\left(>100\right.$ individuals $\left./ \mathrm{m}^{2}\right)$ were found only at five sampling plots. At those plots the dominant geological substrate was tertiary deposits, the altitude was below $280 \mathrm{~m}$ and the coverage of grasses and legumes was close to zero. On the contrary, less than 0.05 individuals $/ \mathrm{m}^{2}$ were found at six plots overlaying on limestone, where the cover of grasses, legumes and of the remaining vegetation was higher than $90 \%$, while the cover of fallen branches was very low $(<2 \%)$.

\subsection{Redundancy analysis}

The total variation in the data set was 1.16 , which is equal to the sum of all unconstrained eigenvalues or the total inertia in species data. The redundancy analysis (RDA) explained $22.8 \%$ of the species variation (P. halepensis, Arbutus unedo, Cistus salviifolius and Erica arborea), while the first axis contributed to $10.1 \%$ and the second axis to $6.1 \%$ of this variability. Only the presence of fallen branches influences positively pine regeneration, while altitude and the percentage cover of the remaining vegetation, stones, legumes and grasses seem to affect it negatively. On the contrary, E. arborea and $A$. unedo seem to be affected positively by altitude (Fig. 2).
Fig. 3 Frequency distribution of regenerated pine densities (individuals per square meter) in the 84 studied plots

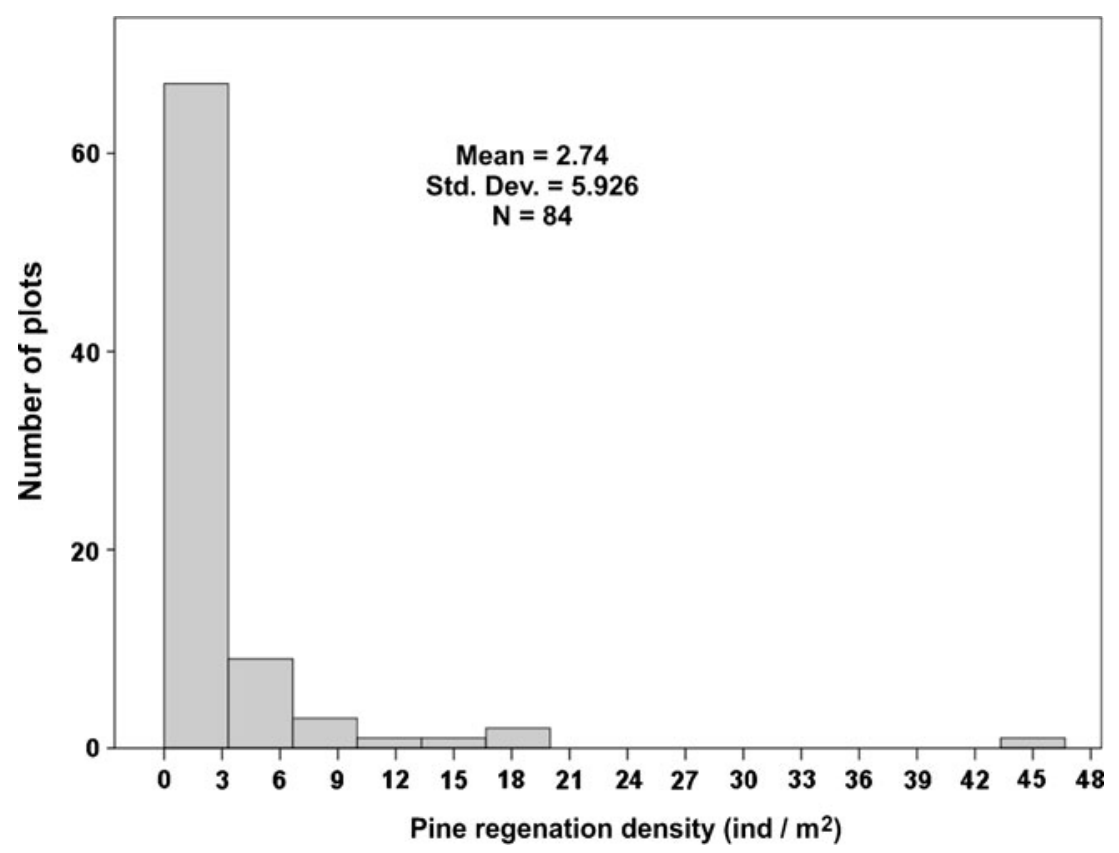




\subsection{Geostatistical, MCE, and final model}

The geostatistical model determined the values of natural pine regeneration in the study area with high accuracy (Fig. 4a). The ME of the actual number of $P$. halepensis seedlings and the mean number of seedlings was 0.003219 and 0.006467 , respectively, while the RMSE were 0.698 and 0.6747 . Both ME values were very close to zero, indicating the low unbiasedness of the RMSE and the Kriging methods used. In turn this indicates that the model's accuracy is high and the predicted values for pines per square meter do not have significant deviation from the observed numbers (ranges 0.08-11.6 pines $/ \mathrm{m}^{2}$ ). The Kriging standard error map (ranges 0.14-0.31 pines $/ \mathrm{m}^{2}$ ) indicated that the maximum error estimation was mainly observed in regions with the lowest pine density prediction values.

Using IDRISI software, terrain slope was found to be correlated negatively to the regeneration, whereas the effect of elevation showed a symmetrical sigmoid curve with maximum control points of the curve of 100 and $340 \mathrm{~m}$, respectively. The bedrock and soil depth play an important role to post-fire regeneration. In this study, according to field data, alluvial rock and tertiary deposits receive maximum values, flysch rocks middle values and values limestone the lowest. The first three factors of Group B $(Q$. coccifera and A. unedo, grasses and stones) showed a negative relationship with the observed pine regeneration, while the last one (percentage cover of fallen wood and branches) showed a positive symmetrical curve where 5 to $15 \%$ cover of branches occupied the upper class of suitability, while it was reducing where the cover ranged from 15 to $21 \%$.

Regarding the MCE model, relevant criterion evaluation maps produced for each one of the two groups (MCE A and MCE B) are presented in Fig. 4b, c. The relative weights, according to AHP results, were assigned as follows. Group A: vegetation 0.604 , geological substrate 0.198 , slope 0.101 , and altitude 0.097 . Group B: percentage cover of $Q$. coccifera and A. unedo 0.452 , grasses cover 0.251 , rock cover 0.148 , and fallen wood with branches 0.149 . The calculated weights are consistent since $\mathrm{CR}_{\text {group } \mathrm{A}}=0.087$ and $\mathrm{CR}_{\text {group } \mathrm{B}}=0.091$. Using Spearman correlation between models either A or B with pine density at the 84 sampling sites, a significant relationship has been revealed ( $r=0.438$ and $r=0.513, p<0.05$, respectively). All possible combinations between A and B were studied and significant correlation $(p<0.05)$ was found between the combined model and the recorded regeneration. By changing each Group's relative contribution, from $\mathrm{A}=90 \%$ and $\mathrm{B}=10 \%$ to $\mathrm{A}=10 \%$ and $\mathrm{B}=90 \%$, differences less than $20 \%$ were observed in correlation coefficient values (Fig. 5). Due to slight variation of these values and as concrete scientific data is missing regarding the relative importance of each Group, equitable utilization rates were decided between the two groups $(\mathrm{A}=50 \%$ and $\mathrm{B}=50 \%)$, since they combined one of the four largest measurements and the lesser degree of subjectivity (Fig. 4d).

Correlation between the final model and the actual number of counted seedlings was very significant and reached $r=$ $0.834, p<0.01$. The classification of the Final MCE model map (Fig. 4e) illustrates that $25 \%$ of the burned area falls in categories "1-5" (low-moderate regeneration), whereas $9.7 \%$ of that area falls in categories " $1-3$ " corresponding to areas with very problematic post-fire pine regeneration. Conversely, $33 \%$ of the burned area falls in categories 9 and 10 with excellent regeneration conditions, while the rest $42 \%$ to categories 6,7 , and 8 (lies in the middle of predicted pine density; Fig. 4).

\section{Discussion}

Although Aleppo pine has a very efficient post-fire reproductive strategy (serotinous cones open and disperse the enclosed mature seeds after the fire), post-fire densities of seedlings vary widely. The main factors that influence these differences are the age of the burned pine forest and the prevailing conditions during the first years of post-fire regeneration (Thanos et al. 1996). In our study, 2 years after the fire, pine seedling density was very high (on average 2-3 individuals $/ \mathrm{m}^{2}$ ). Thanos et al. (1996) found high numbers of pine density (56 individuals $/ \mathrm{m}^{2}$ ) in central Greece, during the first post-fire months, which nevertheless dropped considerably during the first summer to ca. 2.5 seedlings $/ \mathrm{m}^{2}$ and stabilized at ca. 1.5 seedlings $/ \mathrm{m}^{2}$ in the second year. In Spain, 8-9 years after fire, $P$. halepensis regeneration varied greatly among different sites with a mean value of 1.24 individuals $/ \mathrm{m}^{2}$ (s.d. $=3.22$; Pausas et al. 2004a). Competition for light between pine seedlings and other plants as well as among pine individuals has been referred as the main factor for seedling mortality, without excluding prevailing climatic conditions especially during the first post-fire summer (Thanos et al. 1996).

In this study, low-altitude areas with low grass cover overlying tertiary deposits were proved to be the most suitable for pine regeneration. Tertiary deposits are deep enough and offer good support to tree development. The finding is supported by Kazanis (2005) who studied post-fire pine regeneration at stands overlying tertiary deposits, schist and limestone in the Attica region (Central Greece), and found mean pine seedling densities of 39.1, 2.3, and 3.1 individuals $/ \mathrm{m}^{2}$ respectively at the end of the second post-fire year.

Fire intensity, being usually higher in dense mature forests than in mosaic landscapes, may also affect pine regeneration. Pausas et al. (2003) have reported higher pine regeneration in sites severely burned, in comparison to those burned by less intense fires. The fire consumes most of the annual herbs and shrubs, but does not damage the pine serotinous seeds. In addition, both higher post-fire soil $\mathrm{P}$ and high $\mathrm{pH}$, resulting 

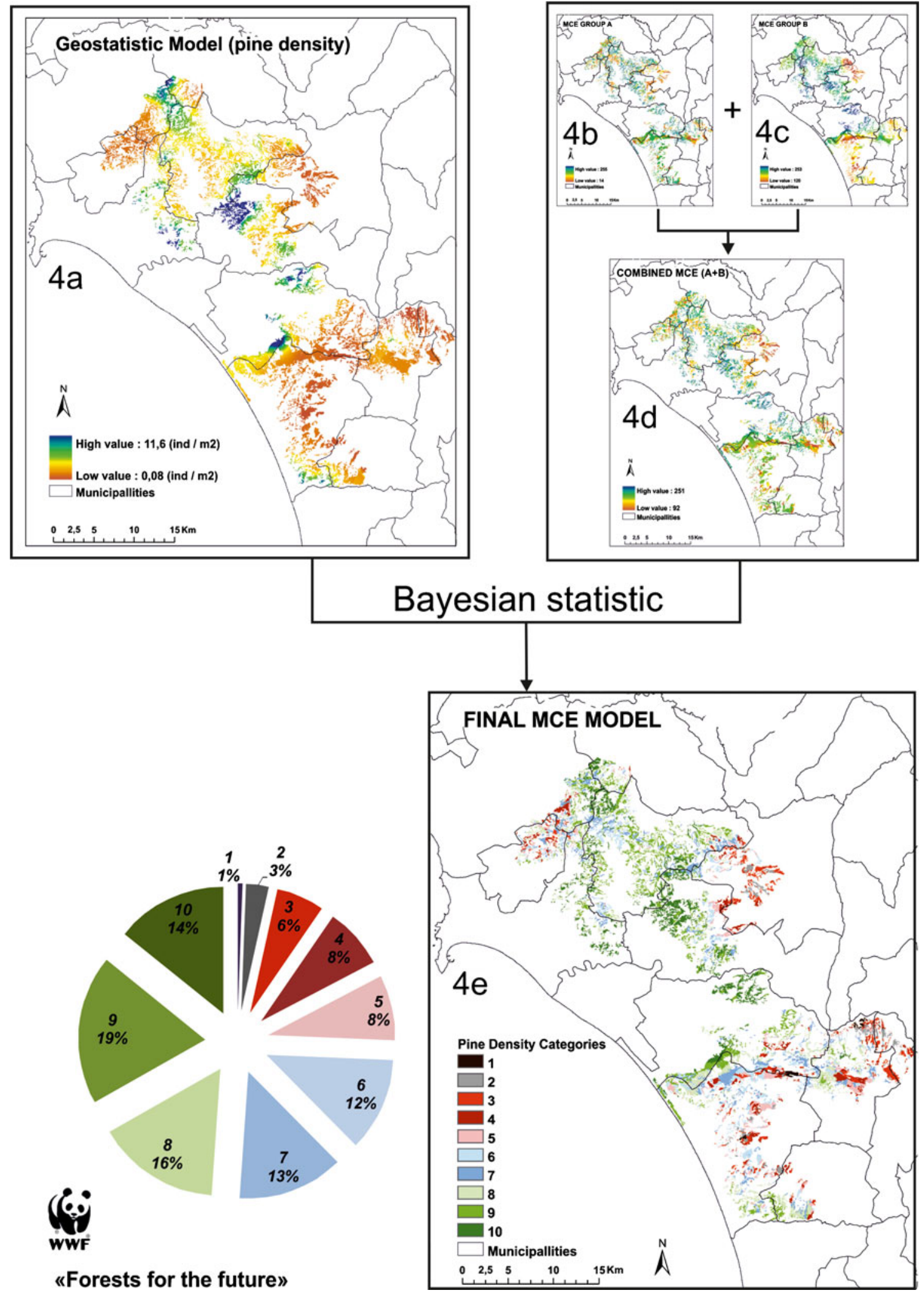

Fig. 4 Maps of pine post-fire density (individuals per square meter) prediction in the study area based on (a) geostatistical model, (b) multicriteria evaluation (MCE) model of group A, (c) MCE model of group B, (d) Integrated $\mathrm{MCE}$ model resulted from group $\mathrm{A}$ and group $\mathrm{B}$

combination, and (e) Bayesian Final MCE model combining (a) and (d). Pine density categories " $1-5$ " indicate low-moderate regeneration, "6-8" medium regeneration, and "9-10" excellent natural pine regeneration. WWF refers to World Wide Fund for Nature 
Fig. 5 Spearman correlation coefficients between recorded regeneration and Groups A and $\mathrm{B}$ using different weights. By changing each Group's relative contribution, from $\mathrm{A}=90 \%$ and $\mathrm{B}=10 \%$ to $\mathrm{A}=10 \%$ and $\mathrm{B}=$ $90 \%$, differences to the base value $(\mathrm{A}=50 \%$ and $\mathrm{B}=50 \%)$ were observed in correlation coefficient values

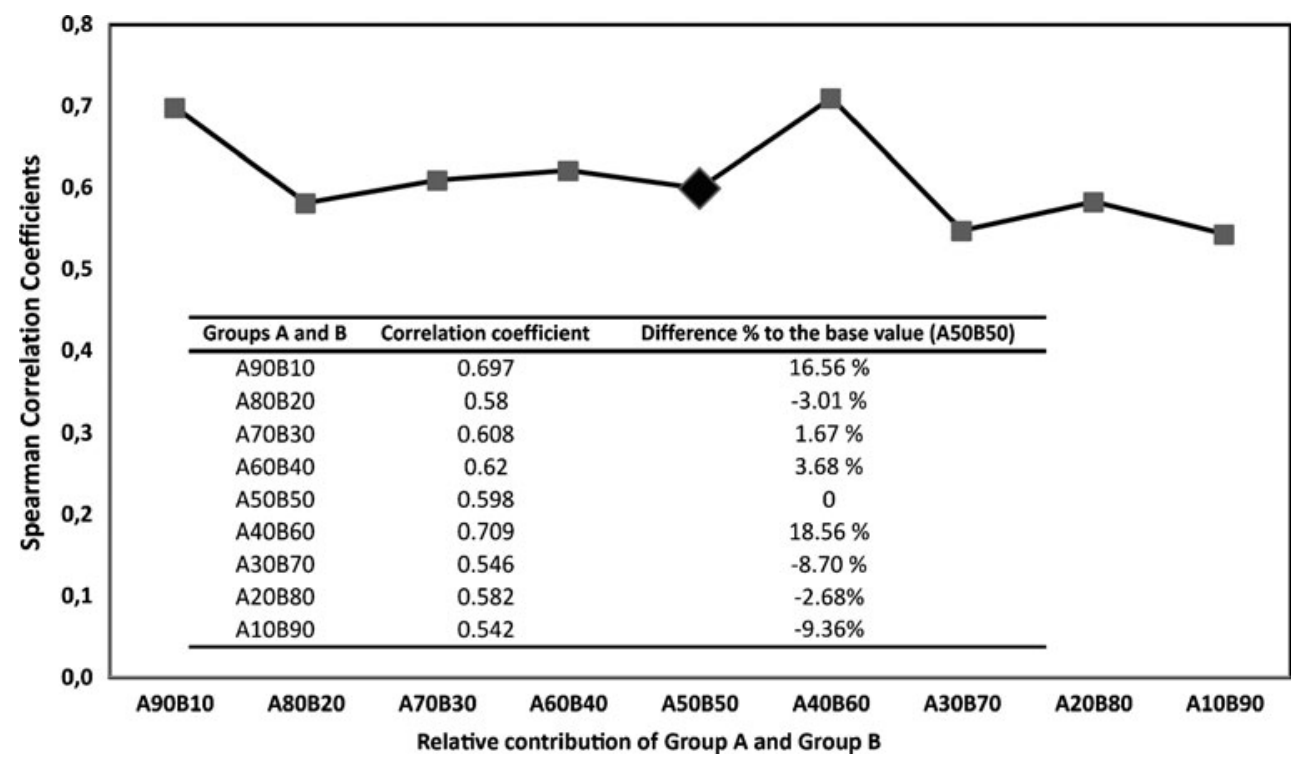

from the thick ash layer near the burned tree trunks, probably favor the presence of high pine seedlings density (Pausas et al. 2004b). In our study, RDA suggested that the amount of branches and wood covering the soil surface is the main source of variation that positively affects pine seedling establishment (Fig. 2). These branches had fallen from burned trees, since no management of the burned area was carried out on the studied plots. According to Pausas et al. (2004a), microclimatic conditions created inside the fallen branches are ideal and play a significant role for this positive relationship.

Our findings show that many factors slow down or even prevent the establishment of pine seedlings, such as the altitude, and the presence of stones, grasses and legumes (Fig. 2). At sampling plots overlying limestone, where different types of vegetation cover (grasses, legumes species, herbs, etc.) reached $100 \%$, only 0.05 individuals $/ \mathrm{m}^{2}$ were present. Pine regeneration has proved to be poor at stands developing on limestone (Kazanis 2005), as soils in question are shallow, discontinuous, very stony, and prone to permeability. Unless a positive relation between pine seedling mortality and percentage cover of vegetation has been found in fertile soils, the coexistence of high number of seedlings with the presence of grasses and other plants is often observed (Pausas et al. 2003). Even though legume species have been proved to be a critical component for ecosystem resilience (Arianoutsou and Thanos 1996), the rate of $P$. halepensis growth probably declines, as it was found in this study, when legumes are combined with other flora components and eventually cover the whole territory. Moreover, on these rocky open areas, seed predation by animals (birds, rodents or ants) during the first year after the fire should not be underestimated, as it has been reported as a significant factor limiting the pine regeneration in other countries (Castro et al. 1999).
Our final model map (Fig. 4e) was classified into ten categories (where $1=$ lowest pine regeneration and $10=$ highest pine regeneration) so that appropriate post-fire management plans can be easily applied for each category and contribute to the achievement of stable post-fire forest environment. In large parts of the burned area (25\%) human's intervention is required, so that $P$. halepensis forests can be satisfactory rehabilitated, whereas in $9.7 \%$ of this area (categories 1,2, and 3) rehabilitation measures, such as restoration of vegetation cover are considered crucial for the recovery of the ecosystems. Areas with medium natural pine regeneration (categories 6-8) must be supported to conserve the existent regeneration. Monitoring plans for seedlings survival as well as complementary plantings should be set on an annual schedule. A very important issue for seedling development in the first post-fire crucial years (especially during dry seasons) is to regulate water so that some drought index thresholds can be avoided and successful seedling growth may be continued. Finally, areas with high pine regeneration (categories 9-10) will need specific silvicultural measures, such as selective thinning to reduce pine intraspecific competition. The enhancement of forest species diversity (with a mix of pines and broad-leaved species) should contribute to the mitigation and restoration actions in the whole region. Without proper ecological restoration, which will take into account the previous landscape heterogeneity that consisted by a mixed agro-forestry mosaic, our extensively burned study area will form a homogeneous post-fire landscape that could promote further catastrophic wildfires. Hence, at the landscape management level, interspersion of land uses should be one of the general management priorities (Moreira et al. 2011).

The aforementioned post-fire $P$. halepensis regeneration variability, shown in the final model map, was affected by 
the relative contribution of the parameters used in this study. As these parameters comprise essential information in determining the areas where poor pine regeneration is expected, they were evaluated and then used as landscape indicators into one integrated GIS-based multi-criteria evaluation to predict and map the regeneration variability. By applying this approach, it is possible to predict woodlands that poorly regenerate after a fire and to organize post-fire mitigation actions. It could also be used as a useful early warning indication for both scientists and woodland managers to act on time. Multicriteria analysis helps towards dealing with complex environmental problems. The method was implemented in Cape Sounion National Park (Arianoutsou et al. 2011) for the post-fire forest resilience by determining all important factors (plant cover, plant species, parent rock material, and slope) and identifying the most important areas in a GIS environment, where measures should be taken accordingly. Finally, sensitivity analysis checked the significance of each factor. AHP and OWA were also used at the same region to identify areas where the preservation and extension of the remaining forest cover and subsequently its biodiversity, were of high impact (Kalivas et al. 2010). In the frame of our combined model, Kriging interpolation method improved the prediction accuracy by $50 \%$, indicating that spatial dependence significantly improved the model's accuracy. More specifically mapping post-fire regeneration through spatial interpolation techniques is based on the positive spatial autocorrelation of the studied variable. Our results suggested that Kriging is an efficient methodology in predicting the aforementioned variable. Vicente-Serano et al. (2011) studied the spatial and temporal patterns of forest regeneration using remote sensing data, taking also account the spatial autocorrelation in the data used. The use of geostatistics has also helped towards estimating the productivity potential of forested areas based on a biophysical model (Benavides et al. 2009). Bayesian statistics was applied to combine the geostatistical and the multi-criteria results. Pereira and Itami (1991) have also integrated two similar models: trend surface and an environmental multiple logistic regression for the development of a habitat suitability model. In the present study, the Kriging interpolated surface was treated as the spatially explicitly model which is based on the spatial autocorrelation of the seedlings, while the MCE model added information on the environmental function and processes affecting post-fire pine regeneration. Bayesian statistics is a technique often used in ecology when prediction of field data is needed to be adjusted with generalized environmental models in order to increase the prediction success (Osborne et al. 2001). Generally, Bayesian theory combines knowledge based mainly on previous studies, literature reviews and expert opinions adjusted by the local conditions and a posterior knowledge based on field experiments or field data. One of the main drawbacks of the Bayesian approach is the subjectivity of the prior knowledge gained ( $\mathrm{Lu} \mathrm{1996)}$ which in our study was encountered by incorporating extended field survey and fuzzy logic in the MCE model. When great Kriging estimation uncertainty exists (areas with big Kriging standard error values), the final prediction result is improved by the multi-criteria method prediction. Furthermore, the non spatial dependent multi-criteria model prediction is improved by the geostatistical estimations, suggesting that Tobler's first law of geography: "Everything is related to everything else, but near things are more related than distant things", applies in post-fire regeneration.

The 2007 wildfires in the prefecture of Ilia, Greece offered the opportunity for the development of a model that can evaluate and predict post-fire $P$. halepensis regeneration. The study demonstrated that MCDM are effective tools in dealing with environmental issues, such as prioritizing areas for landscape assessment after fire. The combination of GIS models increased the prediction success of different levels of pine regeneration. This approach provides management authorities with a sound tool to quickly and accurately assess Aleppo pine post-fire regeneration potential. Further studies could enhance our Bayesian integrated model by testing new modeling techniques as neural network models or logistic models.

Acknowledgments The authors would like to thank Constantina Tarambie and Georgia Christopoulou for their contribution to the field work. We especially thank Ioli Christopoulou and Panagiota Maragou for editing suggestions. The chief editor and the anonymous reviewers are greatly acknowledged for their constructive and valuable comments and recommendations.

Funding This work was carried out in the framework of the "Forests for the Future" program that is implemented by WWF Greece and cofunded by the J.S. Latsis, the A.G. Leventis, and the Bodossakis Foundations and by individual supporters.

\section{References}

Arianoutsou M, Thanos C (1996) Legumes in the fire prone Mediterranean regions: the example of Greece. Int J Wildland Fire 6:77-82

Arianoutsou M, Koukoulas S, Kazanis D (2011) Evaluating post-fire forest resilience using GIS and multi-criteria analysis: an example from Cape Sunion National Park, Greece. Environ Manag 47:384-397

Baeza MJ, Valdecantos A, Alloza JA, Vallejo VR (2007) Human disturbance and environmental factors as drivers of long-term post-fire regeneration patterns in Mediterranean forests. J Veg Sci 18:243-252

Benavides R, Roig S, Osoro K (2009) Potential productivity of forested areas based on a biophysical model. A case study of a mountainous region in northern Spain. Ann For Sci 66:108p10

Burrough PA, McDonnell RA (1998) Principles of geographical information systems. Oxford University Press, New York, p 356

Casady GM, van Leeuwen WJD, Marsh SE (2010) Evaluating postwildfire vegetation regeneration as a response to multiple environmental determinants. Environ Model Assess 15:295-307 
Castro J, Gómez J, Garćia D, Zamora R, Hódar J (1999) Seed predation and dispersal in relict Scots pine forests in southern Spain. Plant Ecol 63:362-369

Corona P, Lamonaca A, Chirici G (2008) Remote sensing support for post fire forest management. iForest 1:6-12

Dìa-Delgado R, Lloret F, Pons X (2003) Influence of fire severity on plant regeneration by means of remote sensing imagery. Int $\mathrm{J}$ Rem Sens 24:1751-1763

Eastman JR (1995) Idrisi for Windows. User's Guide, Version 1.0. Clark Labs. Clark University, Worcester

Hwang CL, Yoon KP (1981) Multiple attribute decision making: methods and applications: a state-of-the-art survey. SpringVerlag, New York, p 259

Jiang H, Eastman JR (2000) Application of fuzzy measures in multicriteria evaluation in GIS. Int J Geogr Inform Sci 14:173-184

Kalivas DP, Kollias VJ, Morakos I (2010). A GIS-based spatial multicriteria evaluation for forest conservation. Case study: National Park of Sounion. CD Proceedings of International congress "Protection and Restoration of the Environment X", Corfu July 2010. Paper Pre1232ACT in CD Proceedings

Kangas J, Kangas A (2005) Multiple criteria decision support in forest management - the approach, methods applied, and experiences gained. For Ecol Manag 207:133-143

Kazanis D (2005) Long-term post-fire regeneration of Aleppo pins forests in Central Greece: patterns of vegetation dynamics. $\mathrm{PhD}$ Thesis, University of Athens

Kohl M, Gertner G (1997) Geostatistics in evaluating forest damage surveys: considerations on methods for describing spatial distributions. For Ecol Manage 95:131-140

Kupfer JA, Farris C (2007) Incorporating spatial non-stationarity of regression coefficients into predictive vegetation models. Landscape Ecol 22:837-852

Lentile L, Holden Z, Smith A, Falkowski M, Hudak A, Morgan P, Lewis S, Gessler P, Benson N (2006) Remote sensing techniques to assess active fire characteristics and post-fire effects. Int J Wildland Fire 15:319-345

Lu Y (1996) Knowledge integration in a multiple classifier system. Appl Intell 6:75-86

Malczewski J (1996) A GIS-based approach to multiple criteria group decision-making. Int J Geogr Inform Syst 10:955-971

Malczewski J (2006) Ordered weighted averaging with fuzzy quantifiers: GIS-based multicriteria evaluation for land-use suitability analysis. Int J Appl Earth Obs Geoinformation 8:270-277

Maselli F, Chiesi M (2006) Evaluation of statistical methods to estimate forest volume in a Mediterranean region. IEEE Trans Geosci Remote Sens 44:2239-2250

Mitri G, Gitas I (2006) Fire type mapping using object-based classification of Ikonos imagery. Int J Wildland Fire 15:457-462

Moreira F, Viedma O, Arianoutsou M, Curt T, Koutsias N, Rigolot E, Barbati A, Corona P, Vaz P, Xanthopoulos G, Mouillot F, Bilgili E (2011) Landscape - wildfire interactions in southern Europe: implications for landscape management. J Environ Manage 92:2389-2402

Orsi F, Geneletti D (2010) Identifying priority areas for forest landscape restoration in Chiapas (Mexico): an operational approach combining ecological and socioeconomic criteria. Landscape Urban Plann 94:20-30

Osborne PE, Alonso JC, Bryant RG (2001) Modelling landscape-scale habitat use using GIS and remote sensing: a case study with great bustards. J Appl Ecol 38:458-471

Pausas JG, Ouadah N, Ferran A, Gimeno T, Vallejo R (2003) Fire severity and seedling establishment in Pinus halepensis woodlands, eastern Iberian Peninsula. Plant Ecol 169:205-213

Pausas JG, Ribeiro E, Vallejo R (2004a) Post-fire regeneration variability of Pinus halepensis in the eastern Iberian Peninsula. For Ecol Manage 204:251-259

Pausas JG, Bladé C, Valdecantos A, Seva JP, Fuentes D, Alloza JA, Vilagrosa A, Bautista S, Cortina J, Vallejo R (2004b) Pines and oaks in the restoration of Mediterranean landscapes of Spain: New perspectives for an old practice - a review. Plant Ecol 171:209-220

Pereira JMC, Itami RM (1991) GIS-based habitat modeling using logistic multiple regression: a study of the Mt. Graham red squirrel. Photogramm Eng Remote Sens 57:1475-1486

Poirazidis K, Zografou K, Kordopatis P, Kalivas D, Arianoutsou M, Kazanis D, Korakaki E (2011). Forecasting natural regeneration of burned Allepo forest (Pinus halepensis) at Ilia prefecture (in greek). Scientific report, WWF Greece, $\mathrm{p} 74$

Ruiz-Gallardo RJ, Castaño S, Calera A (2004) Application of remote sensing and GIS to locate priority intervention areas after wildland fire in Mediterranean systems: a case study from southeastern Spain. Int J Wildland Fire 13:241-252

Saaty RW (1987) The analytic hierarchy process-what it is and how it is used. Math Modelling 9:161-176

Sales MH, Souza CM, Kyriakidis PC, Roberts DA, Vidal E (2007) Improving spatial distribution estimation of forest biomass with geostatistics: a case study for Rondônia, Brazil. Ecol Model 205:221-230

Saltelli A, Chan K, Scott M (2000) Sensitivity analysis, probability and statistics series. Wiley, New York

Thanos C, Daskalakou E, Nikolaidou S (1996) Early post-fire regeneration of a Pinus halepensis forest Mount Parnis, Greece. J Veg Sci 7:273-280

Tsitsoni T (1997) Conditions determining natural regeneration after wildfires in the Pinus halepensis (Miller 1768) forests of Kassandra Peninsula (North Greece). For Ecol Manage 92:199-208

Vicente-Serano SM, Pérez-Cabello F, Lasanta T (2011) Pinus halepensis regeneration after a wildfire in a semiarid environment: assessment using multitemporal Landsat images. Internatinal Journal of Wildland Fire 20:195-208

Webster R, Oliver MA (2007) Geostatistics for environmental scientists, 2nd edn. Wiley, New York, p 318

Xie F, Wang JXG, Xiao DN (2008) Post-fire forest restoration indicated by canopy density in the northern great Hing'An mountains. In: Hong SK, Nakagoshi N, Fu BJ, Morimoto Y (eds) Landscape ecological applications in man-influenced areas: linking man and nature systems. Springer, Dordrecht, pp 359-374 